\title{
ПРИМЕНЕНИЕ ЛИТИЧЕСКИХ БАКТЕРИОФАГОВ ПРИ ХИРУРГИЧЕСКОМ ЛЕЧЕНИИ ПЕРИПРОТЕЗНОЙ ИНФЕКЦИИ ЭНДОПРОТЕЗА ТАЗОБЕДРЕННОГО СУСТАВА (ПИЛОТНОЕ ИССЛЕДОВАНИЕ)
}

\author{
Самохин А.Г. ${ }^{1}$, Фёдоров Е.А. ${ }^{1}$, Козлова Ю.Н. ${ }^{2}$, Тикунова Н.В. ${ }^{2}$, Павлов В.В. ${ }^{1}$, \\ Морозова В.В. ${ }^{2}$, Кретьен C.O. ${ }^{1}$.
}

${ }^{1}$ Федеральное государственное бюджетное учреждение «Новосибирский научно-исследовательский институт травматологии и ортопедии им. Я.Л. Цивьяна» Министерства здравоохранения Российской Федерации, Новосибирск, e-mail: motorist@inbox.ru;

${ }^{2}$ Федеральное государственное бюджетное учреждение науки Институт химической биологии и фундаментальной медичины Сибирского отделения Российской академии наук, Новосибирск

Пилотное исследование применения комбинированной фаго- и антибиотикотерапии при лечении инфекционных осложнений после эндопротезирования тазобедренного сустава в течение полугодового срока наблюдений продемонстрировало эффективность лечения перипротезной инфекции в виде трехкратного уменьшения частоты рецидивов инфекции (с 25 до 8,3\%), наряду с тенденцией к более быстрому (исходя из величин верхнего квартиля) снижению в интервале времени 10-14 дней наблюдения после ревизионного хирургического вмешательства величины содержания СРБ в группе исследования относительно группы сравнения. Вышесказанное позволяет предполагать более эффективное подавление инфекционного процесса при использовании комбинированной фаго- и антибиотикотерапии, однако статистическое подтверждение этой гипотезы требует увеличения популяционной выборки таких пациентов и подтверждения посредством микробиологического исследования (анализ титра бактериофагов для контроля эффективности фаготерапии и утилизации самих бактериофагов в очаге инфекции в ходе проведения фаготерапии).

Ключевые слова: бактериофаг, перипротезная инфекция, эндопротез, сустав

\section{APPLICATION OF THE LYTIC BACTERIOPHAGES DURING SURGICAL TREATMENT OF THE PERIPROSTHETIC INFECTION OF THE HIP JOINT ENDOPROSTHESIS (PILOT STUDY)}

\author{
Samokhin A.G. ${ }^{1}$, Fedorov E.A. ${ }^{1}$, Kozlova Y.N. ${ }^{2}$, Tikunova N.V. ${ }^{2}$, Pavlov V.V. ${ }^{1}$, \\ Morozova V.V. ${ }^{2}$, Kretien S.O. ${ }^{1}$ \\ ${ }^{I}$ Novosibirsk research institute of traumatology and orthopaedics n.a. Ya.L.Tsivyan, Novosibirsk, e-mail: \\ motorist@inbox.ru; \\ ${ }^{2}$ Institute of Chemical Biology and Fundamental Medicine, Siberian Branch of the Russian Academy of Sciences, \\ Novosibirsk
}

Pilot study of clinical application of the combined phage- and antibacterial treatment in patients with infection complications after total hip replacement during six month observation showed that periprosthetic infection recurrence rate were 3 times lower than in antibiotic group (8.3\% and $25 \%$ respectively), including the tendency of slightly fast decrease of such specific infection inflammation marker as C-reactive protein in case of the combined phage- and antibacterial treatment than in antibiotic treatment within 10-14 days after revision surgery. Mentioned above allows to presume more effective infection treatment with the combined phage- and antibacterial treatment but proof of this hypothesis requires an increase of the study population and addition of the bacteriophage titre control for the evaluation of treatment efficacy and bacteriophage utilization.

Keywords: bacteriophage, periprosthetic infection, endoprosthesis, joint

В современной клинической практике с каждым годом возрастает резистентность микроорганизмов к применяемым антибактериальным препаратам, что затрудняет лечение перипротезной инфекции и в итоге приводит к неудовлетворительным результатам лечения $[1]$.

Повсеместное и неоправданное использование антибиотиков во второй половине XX века привело к появлению полирезистентностности микроорганизмов к различным видам 
химических антибактериальных средств, при этом создание новых эффективных и нетоксичных антимикробных средств в фарминдустрии занимает длительное время. В этой связи существует постоянная потребность поиска альтернативных средств антимикробной терапии, а также выбора оптимальных путей их доставки и депонирования, что имеет прикладное значение при выполнении хирургических вмешательств в травматологии и ортопедии для защиты имплантируемой конструкции от возможной инфекции области хирургического вмешательства.

Используемые в настоящее время методы антибактериальной профилактики, а также хирургический метод профилактики формирования липополисахаридной биопленки, продуцируемой пленкообразующими штаммами микроорганизмов на поверхности имплантируемых медицинских изделий и систем, заключающийся в максимально полном иссечении окружающих имплантат инфицированных тканей, не всегда приводят к гарантированной санации области хирургического вмешательства, что в дальнейшем влечет за собой её реинфекцию со всеми вытекающими последствиями, и в частности - повторным формированием среды для жизнедеятельности патогенной микробиоты в области произведенного хирургического вмешательства.

Важным аспектом рассматриваемой проблемы является возможность исходного наличия патогенной микробиоты в окружающих имплантат тканях либо её присоединения гематогенным путем в дальнейшем, что ведет к колонизации имплантата микроорганизмами. Ряд возбудителей, таких как $S$. aureus и его метициллинустойчивые штаммы, способны продуцировать липополисахаридные биопленки в местах своей адгезии (рис. 1) на поверхности металлов, протезов сосудов и других видов имплантатов медицинского назначения, что требует значительного увеличения рабочих концентраций антибиотиков и ухудшает возможность доставки антибактериальных терапевтических средств в воспалительный очаг за счет барьерных свойств бактериальной биопленки, защищающей бактерии от внешних воздействий.

Появление к настоящему времени все большего количества сведений о регуляции бактериальной адгезии, вирулентности и формирования биопленок, бактериальных межклеточных сигналов и механизмах энергетического обмена и биохимических реакций в клетках бактерий привело к расширению понимания дальнейшей стратегии и смещению акцентов в сторону превентивных мер, направленных в первую очередь на предупреждение колонизации имплантируемых устройств и систем патогенными микроорганизмами, нарушению формирования либо непосредственному повреждению биопленок с блокированием межклеточных сигналов [4] и дестабилизации систем поддержания гомеостаза патогенных микроорганизмов [12], наряду с применением неспецифических 
бактерицидных препаратов или их комбинаций.

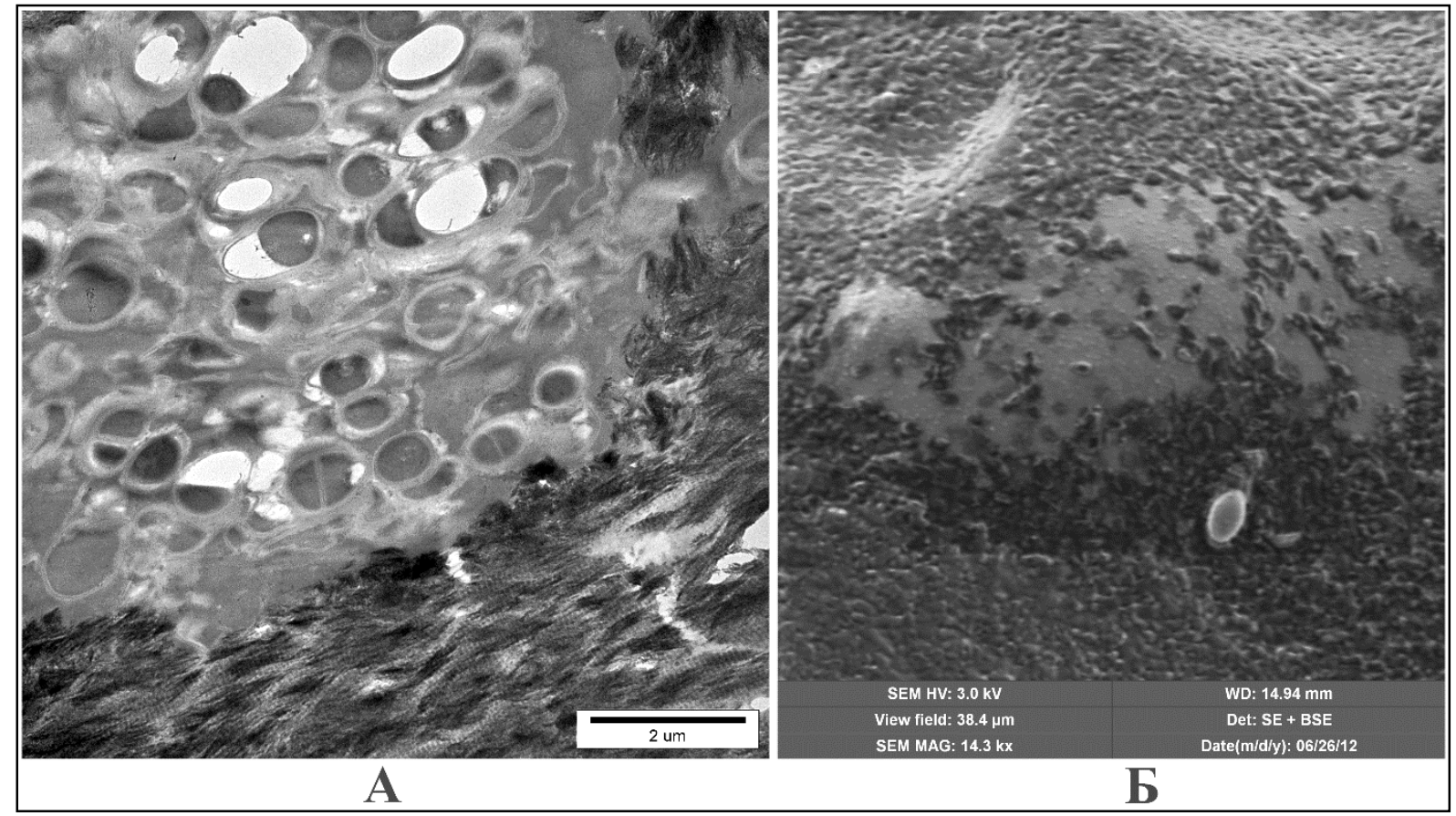

Рис. 1. Электронная микроскопия образиов биоматериала. A-Биопленка, образованная $S$. aureus, выделенная с поверхности ортопедического металлоимплантата. Трансмиссионная электронная микроскопия (фото сделано авторами). Б-Сплошная колонизация имплантата из чистого титана Ps. aeruginosae. Сканирующая электронная микроскопия (фото сделано авторами)

Одним из существующих на сегодняшний день методов борьбы с бактериальными инфекциями, лишенных таких недостатков антибиотиков, как снижение концентрации агента с течением времени и возможные аллергические реакции, являются естественные вирусы, инфицирующие бактерии - бактериофаги [6]. В силу особенностей строения и активности бактериофаги способны преодолевать экзополимерный субстрат биопленок, вызывая значительные изменения в самих биопленках [13] и уничтожать бактерии внутри биопленки, что в случае антибиотиков возможно далеко не для каждого антибиотика. Именно поэтому применение литических бактериофагов в травматологии и ортопедии представляет большой интерес с точки зрения фаготерапии инфекций, вызванных антибиотикорезистентными и биопленкообразующими штаммами бактерий.

Цель исследования. Определить характер изменений величин индикаторов инфекционного процесса (С-реактивного белка и величины скорости оседания эритроцитов) и частоту рецидивов инфекционного процесса при выполнении сравнительного исследования рутинной антибиотикотерапии инфекционных осложнений после эндопротезирования тазобедренного сустава в сравнении с комбинированной антибиотико- и фаготерапией, назначаемых в течение первых 14 суток от момента ревизионного хирургического вмешательства. 
Материалы и методы. В настоящее пилотное проспективно-ретроспективное нерандомизированное сравнительное гипотезопорождающее исследование было включено 28 пациентов с инфекционными осложнениями после эндопротезирования тазобедренного сустава, из них в группу исследования были включены проспективно 12 пациентов (8

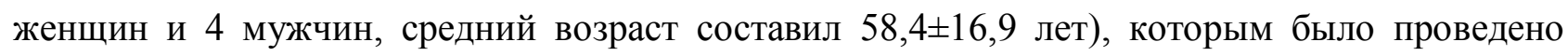
хирургическое лечение в объеме одноэтапного цементного ревизионного эндопротезирования тазобедренного сустава с одновременным назначением этиотропного лечения инфекции в виде фаготерапии и антибиотикотерапии.

В группу сравнения было включено ретроспективно 16 пациентов (7 женщин и 9 мужчин, средний возраст составил 55,0土11,0 лет), которым было проведено хирургическое лечение в объеме одноэтапного цементного ревизионного эндопротезирования тазобедренного сустава с одновременным назначением этиотропного лечения инфекции в виде антибиотикотерапии.

Для систематизации больных использовали классификации Coventry-Fitzgerald и Parvizi J. et al. $[12,13]$. При проведении диагностических мероприятий критерием наличия перипротезной инфекции (ППИ) были лабораторные признаки синдрома системного воспаления (увеличение содержания С-реактивного белка (СРБ), ускорение скорости оседания эритроцитов (СОЭ), которые оценивали на 2-3, 7 и 10-14 сутки после операции, а также положительный результат бактериологического исследования. По результатам бактериологического исследования структура возбудителей ИОХВ в группах исследования и сравнения по этиологии выглядела следующим образом (Табл. 1).

Таблица 1

этиологическая структура возбудителей ИОХВ в группах исследования и сравнения по результатам бактериологического анализа

\begin{tabular}{|l|c|c|c|c|c|}
\hline \multicolumn{1}{|c|}{$\begin{array}{l}\text { Возбудитель } \\
\text { случаев }\end{array}$} & $\begin{array}{c}\text { S.epidermidis } \\
\text { (MSSE) }\end{array}$ & $\begin{array}{c}\text { S.epidermidis } \\
\text { (MRSE) }\end{array}$ & $\begin{array}{c}\text { S.aureus } \\
\text { (MSSA) }\end{array}$ & $\begin{array}{c}\text { Enterococcus } \\
\text { faecalis }\end{array}$ & Прочие \\
\hline Группа исследования & 6 & 3 & 3 & 0 & 0 \\
\hline Группа сравнения & 4 & 3 & 6 & 2 & 4 \\
\hline
\end{tabular}

Примечание $\kappa$ таблице 1: у ряда пациентов в образцах биоматериала были идентифицированы одновременно несколько микроорганизмов.

В случае развития ранней перипротезной инфекции пациенты были госпитализированы в короткий срок с момента манифестации клинической картины, тогда как пациенты с поздней перипротезной инфекцией поступали с задержкой в 2-3 недели, поскольку проходили лечение по месту жительства. 
Фаготерапию в настоящем исследовании применяли путем введения бактериофагов производства ФГУП НПО «Микроген» (Россия) через дренажи, выводимые накожно после выполнения хирургического вмешательства. Штаммы фагов применяли этиотропные по отношению к выявленным микроорганизмам.

При выполнении микробиологического исследования после идентификации патогенного микроорганизма и определения антибиотикограммы проводили тестирование чувствительности выявленных микроорганизмов к соответствующему коммерческому бактериофагу производства ФГУП НПО «Микроген» (Россия) (обычно не менее 2-х партий бактериофагов) [1] и контроль за проводимой фаготерапией проводили согласно разработанному нами способу «Способ оценки эффективности фаготерапии при лечении инфекционных заболеваний» (приоритетная справка №2016132090 от 03.08.2016) [3]. Титр бактериофагов в биоматериале пациента определяли через сутки, на четвертый день и на десятые сутки после начала фаготерапии.

Хирургическое лечение у пациентов обеих групп выполняли одноэтапно - удаление эндопротеза и проведение цементного реэндопротезирования с обязательной прессутизацией цемента.

Операцию завершали дренированием раны, дренажи устанавливали субфасциально к шейке бедренного компонента и выводили через отдельный прокол на боковой поверхности бедра, а саму рану послойно ушивали с применением внутрикожных швов.

Средняя длительность госпитализации пациентов группы исследования в настоящем

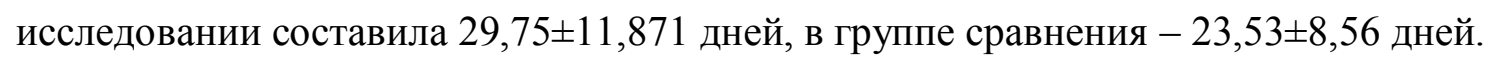

Пациентам группы исследования в течение 10 суток после завершения операции в дренажи вводили коммерческий бактериофаг к выделенному микроорганизму объемом до 20 мл; у пациентов группы сравнения бактериофаг не применяли.

Поскольку монотерапию бактериофагами у пациентов группы исследования в настоящем исследовании не применяли, то всем пациентам этой группы в послеоперационном периоде была дополнительно назначена этиотропная антибактериальная терапия на срок до 12 недель по следующим схемам:

В стационарных условиях (первые две недели) - парентерально вводили ванкомицин в дозе 1,0 г два раза в сутки, внутривенно капельно и цефазолин в дозе 2,0 г три раза в сутки, внутривенно капельно [14].

После выписки, на амбулаторном этапе пациентам были назначены пероральные антибиотики по следующим схемам:

1. Ципрофлоксацин в дозе 0,5г х два раза в сутки в течение 21 дня и рифампицин в дозе 450мг х два раза в сутки в течении 10 недель; 
2. Триметоприм/сульфаметоксазол в дозе 480 мг два раза в сутки в течение 1 месяца, затем доксициклин в дозе 100 мг два раза в сутки в течение 8 недель.

В группе сравнения антибиотикотерапию назначали с учетом чувствительности микроорганизмов к препаратам по следующим схемам:

В стационаре:

1. Ц Цефазолин 2,0 г три раза в сутки на срок до 2 недель;

2. Ванкомицин 1,0 г два раза в сутки на срок до 4 недель + даптомицин 0,5 г один раз в сутки на срок до 3 недель;

3. Ц Ципрофлоксацин 0,4 г два раза в сутки на срок до 4 недель;

4. Цефазолин 2,0 г три раза в сутки + даптомицин 0,5 г один раз в сутки на срок до 2 недель;

5. Ванкомицин 1,0 г х два раза в сутки на срок до 1 недели и цефазолин 2,0 г три раза в сутки на срок до 3 недель;

6. Ванкомицин 1,0 г х два раза в сутки + рифампицин 0,6 г один раз в сутки на срок до 2 недель.

После выписки пациентам этой группы назначали ципрофлоксацин в дозе 0,5 г х два раза в сутки в течение 3-5 недель либо рифампицин 0,3 г один раз в сутки в течение 3 месяцев.

Обработку полученных результатов исследования проводили при помощи программного обеспечения SPSS v19.0 путем вычисления описательных статистик и сравнения значений переменных, относящихся к дискретной шкале. Все описательные статистики представлены в виде непараметрических статистик - медианы $(\mathrm{Me})$ и нижнего и верхнего квартилей [Q1; Q3], за исключением возраста пациентов и сроков их пребывания в стационаре, которые представлены в виде средней и стандартного отклонения. С учетом малого размера популяционной выборки сравнения проводили непараметрическими методами: внутригрупповые сравнения проводили парным ранговым методом Уилкоксона с поправкой на множественность сравнений, для проведения межгрупповых сравнений использовали метод Уилкоксона-Манна-Уитни.

Различия сравниваемых величин при внутригрупповом сравнении анализировали с учетом поправки на множественность сравнений и считали значимыми при значениях, не превышающих порогового уровня двунаправленной статистической значимости $(\alpha=0,05 / 5$ $=0,01)$. При межгрупповом сравнении пороговым уровнем двунаправленной статистической значимости считали $\alpha=0,05$.

Результаты и их обсуждение. При выполнении микробиологического контроля в первые 14 дней после операции лишь у двух из 12-ти пациентов группы исследования на 4- 
ые сутки фаготерапии была идентифицирована смена патогенного микроорганизма, что потребовало отмены ранее назначенной фаготерапии и смены антибактериальной терапии с назначением другого антибиотика на срок до 12 недель.

У остальных 10-ти пациентов группы исследования в образцах раневого отделяемого роста ранее идентифицированного патогенного микроорганизма не отмечено. Анализ титра бактериофага в соответствии с предложенным нами способом показал, что содержание бактериофагов в раневом отделяемом достигало значений $\geq 10^{4}$ БОЕ/мл в первые трое суток после начала фаготерапии (при этом концентрация бактериофагов в ежесуточно вводимом пациентам через дренажи препарате была терапевтической и составляла не менее $10^{6}$ БОЕ/мл). Фаготерапию при этом продолжали в течение 10 суток после операции, учитывая изменение содержания контролируемых маркеров воспаления в образцах биоматериала пациентов.

Что касается изменений величин контролируемых параметров в настоящем исследовании, то оно характеризовалось следующими изменениями: при внутригрупповом сравнении в каждой из двух изучаемых групп пациентов было установлено, что содержание СРБ и величина СОЭ возросли уже на 2-3 сутки после хирургического вмешательства, однако впоследствии происходило их постепенное снижение до конца срока наблюдений. При этом в группе исследования содержание СРБ продемонстрировало статистически значимое снижение в интервале времени с 7-ых до 10-14-ых суток практически в 2,2 раза (p $=0,009)$, и аналогичным образом значимое различие было зарегистрировано в этой же группе по величине СОЭ в указанном промежутке времени - отмечено снижение в 1,18 раза ( $=0,001)$ (табл. 2, рис. 2 и 3). Что касается группы сравнения, то при анализе внутригрупповых изменений контролируемых параметров величин СОЭ и содержания СРБ статистически значимых различий не отмечено.

В ходе выполнения межгруппового сравнения при сопоставлении полученных в группе исследования результатов с таковыми в группе сравнения статистически значимых различий во всех временных точках измерений не отмечено (табл. 2), но тенденция изменений медиан контролируемых параметров была такова, что медианные значения СРБ в обеих группах к 10-14-ым суткам практически сравнялись (14,79 и 12,73 мг/мл соответственно), тогда как величины СОЭ сохраняли относительно постоянные уровни, хоть и с тенденцией к снижению. Более того, для величин СОЭ была отмечена тенденция к повышенным значениям СОЭ в группе исследования на протяжении всего исследования, а на 7-ые сутки было зарегистрировано недостоверное увеличение в 1,5 раза (p = 0,061), практически на границе принятого нами уровня $\alpha$ для межгрупповых сравнений, что позволяет предполагать, что с увеличением размера популяционной выборки в группе 
исследования возможно получение статистически значимых различий по данному параметру в указанной временной точке измерений.

Отдельно необходимо остановиться на антибиотикорезистентности выделенных из биоматериала пациентов штаммов микроорганизмов. Всего было идентифицировано шесть таких пациентов: по три пациента из групп исследования и сравнения соответственно (табл. 3), у всех этих пациентов в качестве возбудителя был выделен метициллинрезистентный штамм S.epidermidis (MRSE) (табл. 1). Однако из-за малочисленности таких пациентов в рассматриваемой популяционной выборке, дополнительный анализ по контролируемым параметрам величин СОЭ и СРБ с внутригрупповой градацией пациентов по резистентности микроорганизмов к антибиотикотерапии мы не проводили.

Общий взгляд на изменение значений контролируемых в исследовании параметров говорит о разнонаправленности изменений величин СОЭ и СРБ в группах пациентов с течением времени: прогрессирующая тенденция к снижению содержания СРБ, при одновременной тенденции к сохранению после хирургического лечения практически неизменных величин СОЭ в обеих группах пациентов. Однако в отличие от такого параметра, как величина СОЭ, которая может изменяться из-за множества различных факторов, включая пол и возраст пациента, на уровень СРБ не влияет ни один из известных факторов, кроме наличия и степени выраженности инфекционного воспаления [8], поскольку содержание СРБ обычно существенно возрастает при инфекционных процессах, в т.ч. при остеомиелите и перипротезной инфекции [11]. Период полувыведения из плазмы и уровень катаболизма СРБ являются постоянными величинами почти при любых условиях, поэтому содержание СРБ в плазме определяется только уровнем его синтеза, который, в свою очередь, зависит исключительно от наличия и тяжести инфекционного процесса [8].

Зарегистрированная в нашем исследовании между группами пациентов общая тенденция к увеличению содержания СРБ на 2-3 сутки, выражавшаяся в увеличении среднего содержания СРБ у пациентов группы исследования, позволяет предполагать более выраженную остроту инфекционного процесса у пациентов, получавших комбинированную фаго- и антибиотикотерапию, равно как и дает возможность предполагать рост содержания маркеров острофазовых реакций (к которым относится и СРБ) в ответ на введение бактериофагов, которые способны вызвать резкое сокращение популяции патогенных микроорганизмов, что может сопровождаться выбросом значительного количества бактериальных токсинов во внутреннюю среду организма и спровоцировать сильный острофазовый ответ иммунной системы. 
Средние величины содержания контролируемых маркеров воспаления в течение 10-14 суток после операции в группе исследования $(\mathrm{n}=12)$ и в группе сравнения $(\mathrm{n}=17)$ (данные представлены в виде Мe [Q1; Q3])

\begin{tabular}{|c|c|c|c|c|}
\hline Параметр & $\begin{array}{c}\text { Группа } \\
\text { исследования } \\
\text { (фаготерапия + } \\
\text { АБТ), СРБ, мг/л } \\
\end{array}$ & $\begin{array}{c}\text { Группа сравнения } \\
\text { (АБТ), СРБ, мг/л }\end{array}$ & $\begin{array}{c}\text { Группа исследования } \\
\text { (фаготерапия + АБТ), } \\
\text { СОЭ, мм/ч }\end{array}$ & $\begin{array}{l}\text { Группа сравнения } \\
(\text { АБТ), СОЭ, мм/ч }\end{array}$ \\
\hline До операции & $\begin{array}{c}27,29 \\
{[20,50 ; 38,82]} \\
\end{array}$ & $\begin{array}{c}35,5 \\
{[14,90 ; 50,33]} \\
\end{array}$ & $\begin{array}{c}51,50 \\
{[35,25 ; 82,00]} \\
\end{array}$ & $\begin{array}{c}44,5 \\
{[31,50 ; 86,75]} \\
\end{array}$ \\
\hline $\begin{array}{c}\text { Уровни } \\
\text { значимости } \\
\text { (межгрупповое } \\
\text { сравнение) } \\
\end{array}$ & 0,698 & & 0,846 & \\
\hline $\begin{array}{c}2-3 \text { сутки после } \\
\text { операции }\end{array}$ & $\begin{array}{c}94,15 \\
{[46,22 ; 160,24]} \\
\end{array}$ & $\begin{array}{c}51,5 \\
{[31,77 ; 112,90]} \\
\end{array}$ & $\begin{array}{c}72 \\
{[43,75 ; 100,75]} \\
\end{array}$ & $\begin{array}{c}53 \\
{[31,50 ; 80,00]} \\
\end{array}$ \\
\hline $\begin{array}{c}\text { Уровни } \\
\text { значимости } \\
\text { (внутригрупповое } \\
\text { сравнение) }\end{array}$ & $\begin{array}{c}\text { До операции - } \\
\text { через 2-3 суток: } \mathrm{p} \\
=0,049\end{array}$ & $\begin{array}{c}\text { До операции - через } \\
2-3 \text { суток: } p=0,065\end{array}$ & $\begin{array}{l}\text { До операции - через } \\
2-3 \text { суток: } p=0,025\end{array}$ & $\begin{array}{c}\text { До операции - } \\
\text { через 2-3 суток: } \\
\text { p }=0,632\end{array}$ \\
\hline $\begin{array}{c}\text { Уровни } \\
\text { значимости } \\
\text { (межгрупповое } \\
\text { сравнение) } \\
\end{array}$ & 0,165 & & 0,156 & \\
\hline $\begin{array}{l}7 \text { сутки после } \\
\text { операции }\end{array}$ & $\begin{array}{c}38,92 \\
{[17,80 ; 54,79]}\end{array}$ & $\begin{array}{c}23,72 \\
{[16,70 ; 51,52]}\end{array}$ & $\begin{array}{c}78,5 \\
{[63,75 ; 96,00]}\end{array}$ & $\begin{array}{c}52 \\
{[27,25 ; 90,75]}\end{array}$ \\
\hline $\begin{array}{c}\text { Уровни } \\
\text { значимости } \\
\text { (внутригрупповое } \\
\text { сравнение) }\end{array}$ & $\begin{array}{c}\text { До операции - } \\
\text { через } 7 \text { суток: } \mathrm{p}= \\
0,519 ; \text { через } 2-3 \\
\text { суток }- \text { через } 7 \\
\text { суток: } \mathrm{p}=0,02 \\
\end{array}$ & $\begin{array}{c}\text { До операции - через } \\
7 \text { суток: } p=0,860 ; \\
\text { через } 2-3 \text { суток - } \\
\text { через } 7 \text { сугок: } p= \\
0,025 \\
\end{array}$ & $\begin{array}{c}\text { До операции - через } 7 \\
\text { суток: } p=0,02 ; \text { через } \\
2-3 \text { суток - через } 7 \\
\text { суток: } p=0,278\end{array}$ & $\begin{array}{c}\text { До операции - } \\
\text { через } 7 \text { суток: } \mathrm{p}= \\
0,991 ; \text { через } 2-3 \\
\text { суток }- \text { через } 7 \\
\text { суток: } \mathrm{p}=1,0 \\
\end{array}$ \\
\hline $\begin{array}{c}\text { Уровни } \\
\text { значимости } \\
\text { (межгрупповое } \\
\text { сравнение) } \\
\end{array}$ & 0,537 & & 0,061 & \\
\hline $\begin{array}{c}\text { 10-14 сутки после } \\
\text { операции }\end{array}$ & $\begin{array}{c}14,79 \\
{[10,87 ; 26,22]}\end{array}$ & $\begin{array}{c}12,73 \\
{[9,00 ; 31,97]}\end{array}$ & $\begin{array}{c}66,5 \\
{[53,50 ; 79,50]}\end{array}$ & $\begin{array}{c}43,5 \\
{[31,25 ; 76,75]}\end{array}$ \\
\hline $\begin{array}{c}\text { Уровни } \\
\text { значимости } \\
\text { (внутригрупповое } \\
\text { сравнение) }\end{array}$ & $\begin{array}{c}\text { До операции - } \\
\text { через } 10-14 \text { суток: } \\
\text { p = 0,064; Через } 7 \\
\text { суток }- \text { через } 10- \\
14 \text { суток: } \mathbf{p}=\mathbf{0 , 0 0 9} \\
\end{array}$ & $\begin{array}{c}\text { До операции - через } \\
10-14 \text { суток: } \mathrm{p}= \\
0,159 \text {; Через } 7 \text { суток } \\
\text { - через } 10-14 \text { суток: } \\
\text { p }=0,025 \\
\end{array}$ & $\begin{array}{c}\text { До операции - через } \\
10-14 \text { суток: } \mathbf{p}= \\
0,248 ; \text { Через } 7 \text { суток - } \\
\text { через 10-14 суток: } \mathbf{p}= \\
\mathbf{0 , 0 0 1} \\
\end{array}$ & $\begin{array}{c}\text { До операции - } \\
\text { через 10-14 суток: } \mathrm{p} \\
=0,668 ; \text { Через } 7 \\
\text { суток - через 10-14 } \\
\text { суток: } \mathrm{p}=0,073 \\
\end{array}$ \\
\hline $\begin{array}{c}\text { Уровни } \\
\text { значимости } \\
\text { (межгрупповое } \\
\text { сравнение) }\end{array}$ & 1,0 & & 0,133 & \\
\hline
\end{tabular}

Примечание: АБТ - антибиотикотерапия 


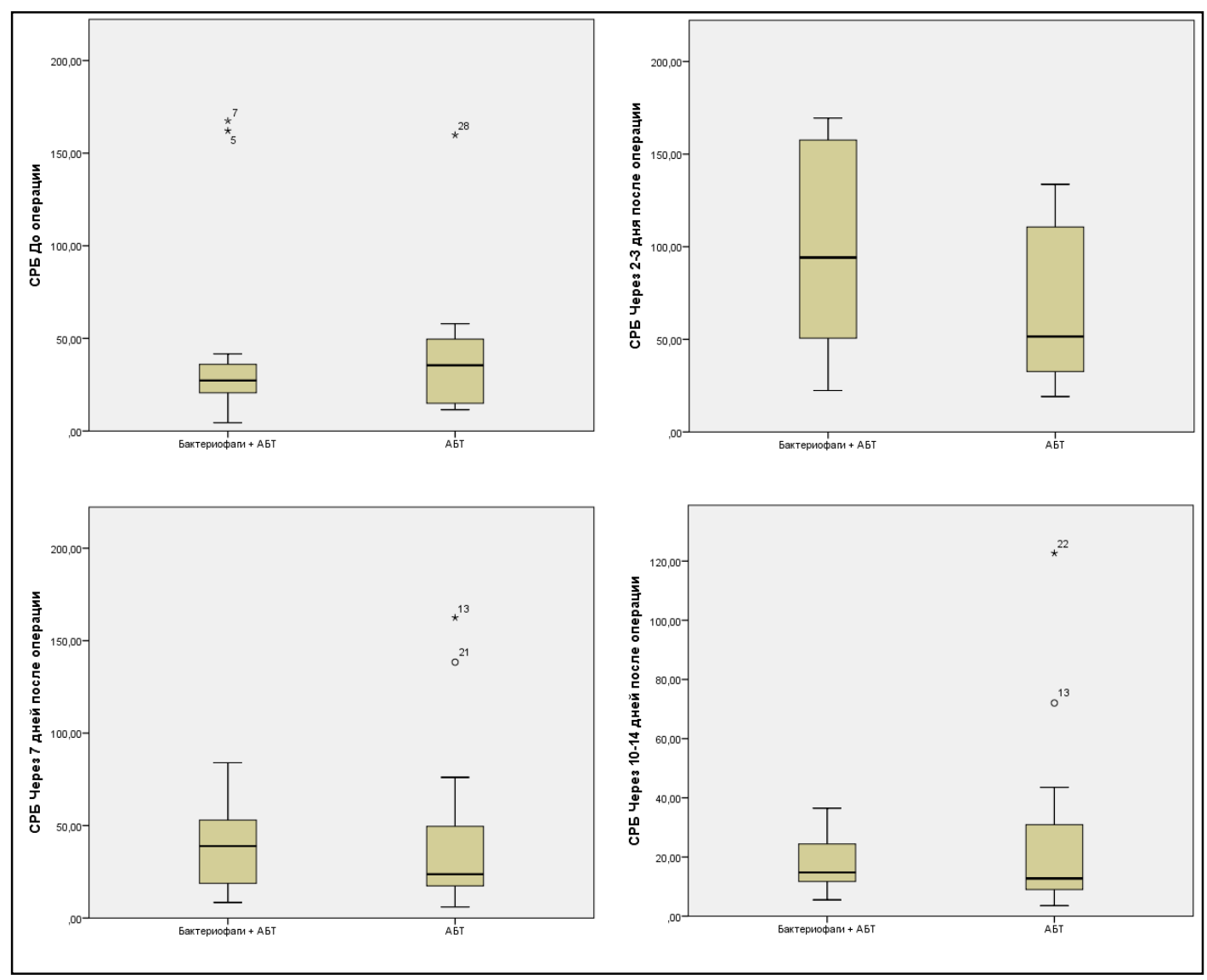

Рис. 2. Коробчатая диаграмма величин СРБ в группах паџиентов с градацией по типу лечения (фаготерапия + антибиотикотерапия (АБТ) и терапия антибиотиками)

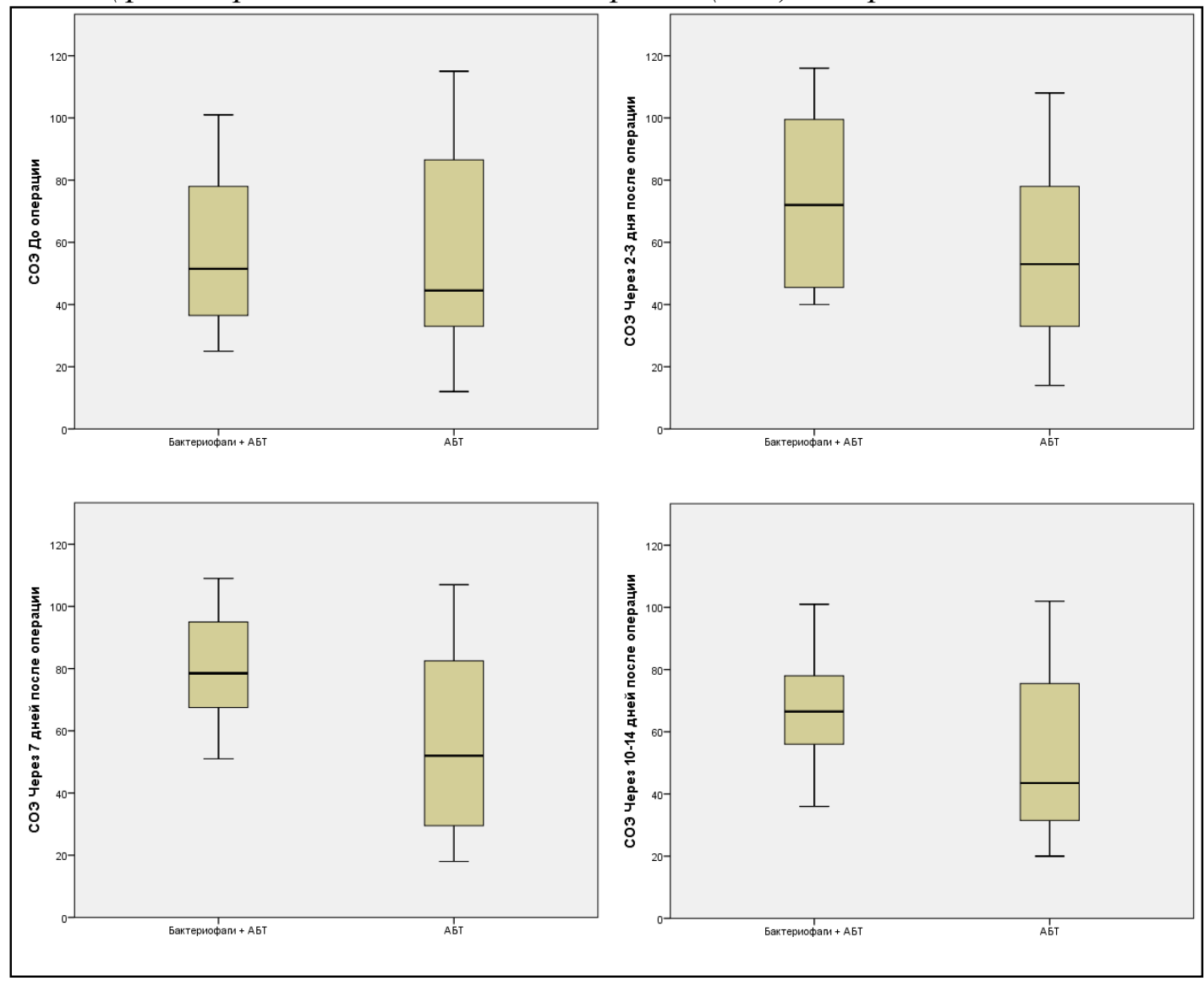


Рис. 3. Коробчатая диаграмма величин СОЭ в группах пащчентов с градащией по типу лечения (фаготерапия + антибиотикотерапия (АБТ) и терапия антибиотиками)

При этом надо отметить, что тенденция к последовавшему на 10-14-ые сутки после ревизионной операции более быстрому (исходя из величин верхнего квартиля) снижению содержания СРБ в группе исследования, наряду с отсутствием экстремально высоких значений (тогда как в группе сравнения с 7 по 10-14 сутки сохранялись два статвыброса свыше 60 мг/л), косвенно указывала на возможно более эффективное подавление инфекционного процесса при использовании комбинированной фаго- и антибиотикотерапии. Другим немаловажным фактором является то, что использованные нами на стационарном этапе лечения в группе исследования антибиотики не являются биопленкопроникающими, и хотя мы не проводили анализ штаммов микроорганизмов на предмет их способности к биопленкообразованию, вероятность биопленкообразования полностью исключать нельзя, особенно с учетом длительности течения инфекционного процесса у изученных пациентов до выполнения им ревизионного хирургического вмешательства - в таком случае воздействие на микроорганизмы, содержащиеся в различных слоях биопленки, могли оказать только бактериофаги, которые обладают специальными ферментами, позволяющими им проникать сквозь биопленку и разрушать её липополисахаридную структуру [7, 15].

Что касается характеристики частоты рецидивов ППИ в исследуемой популяции, то за полугодовой период наблюдений в группе исследования был зарегистрирован лишь один рецидив ППИ (при этом фаготерапия не была проведена в полном объеме из-за смены микроорганизма со S.epidermidis MSSE на S.haemolyticus MRSH на 4-ые сутки послеоперационного периода, несмотря на проводимую антибактериальную терапию), тем самым частота рецидивов составила $(1 * 100) / 12=8,3 \%$, тогда как группе сравнения за этот же промежуток времени было зарегистрировано четыре рецидива ППИ, а частота рецидивов составила $(4 * 100) / 16=25 \%$, что практически в три раза больше, чем в группе исследования.

Таким образом, принимая во внимание то, что рецидив ППИ был зарегистрирован лишь у одного пациента, то итоговая частота эффективности комбинированной фаго- и антибиотикотерапии (выраженная в частоте безрецидивных случаев в изучаемой популяции) в настоящем пилотном исследовании составила $100 \%-((1 * 100 \%) / 12)=91,7 \%$, а итоговая частота эффективности антибиотикотерапии без применения бактериофагов составила 100 $((4 * 100) / 16)=75 \%$.

Впрочем, необходимо упомянуть также о том, что причины появления таких тенденций различия в результатах лечения могут быть связаны в том числе и с различными схемами антибиотикотерапии, которые были применены в группах пациентов, что является одним из ограничений данного исследования (наряду с небольшой популяционной 
выборкой), поэтому логичным продолжением данного пилотного исследования было бы изучение результатов лечения ППИ у большей по размеру популяции пациентов с идентичными схемами антибиотикотерапии и наличием либо отсутствием бактериофагов в схеме лечения ППИ.

Все вышесказанное позволяет выдвинуть гипотезу о том, что использование фаготерапии в комбинации с антибиотикотерапией, при условии должного статистического обоснования расчета для увеличения популяционной выборки пациентов, получавших такую комбинированную терапию, может продемонстрировать статистически значимое различие по такому маркеру воспаления, как СРБ, в интервале времени 10-14 дней после хирургического вмешательства, однако для этого необходимо одновременное подтверждение посредством микробиологического исследования (анализ титра бактериофагов для контроля эффективности фаготерапии и утилизации самих бактериофагов в очаге инфекции в ходе проведения фаготерапии).

\section{Выводы:}

1. В группе исследования после проведенного лечения частота рецидивов перипротезной инфекции в течение полугода наблюдений составила 8,3\%, тогда как группе сравнения за этот же промежуток времени частота рецидивов была практически в три раза больше, составив $25 \%$.

2. Тенденция к более быстрому (исходя из величин верхнего квартиля) снижению в интервале времени 10-14 дней наблюдения после ревизионного хирургического вмешательства величины содержания СРБ в группе исследования относительно группы сравнения позволяет предполагать более эффективное подавление инфекционного процесса при использовании комбинированной фаго- и антибиотикотерапии, однако статистическое подтверждение этой гипотезы требует увеличения популяционной выборки таких пациентов.

\section{Список литературы}

1. Рациональное применение бактериофагов в лечебной и противоэпидемической практике. Федеральные клинические рекомендации [Текст] / Б.И. Асланов, Л.П. Зуева, Л.А. Кафтырева, А.Г. Бойцов, В.Г. Акимкин, А.А. Долгий, Е.Б. Брусина, О.М. Дроздова - М.: [б.и.], 2014. -39 с.

2. Божкова С.А. Этиологическая структура и антибиотикорезистентность ведущих возбудителей перипротезной инфекции в стационаре травматолого-ортопедического профиля [Текст] / С.А. Божкова, Т.М. Петрова, Н.Э. Мирзоев // Рациональная 
фармакотерапия и клиническая фармакология: сб. науч. матер. V Конгресса. - СПб., 2010. C. $49-52$.

3. Павлов В.В., Самохин А.Г., Козлова Ю.Н., Федоров Е.А., Прохоренко В.М., Кретьен С.О., Тикунова Н.В., Морозова В.В. Способ оценки эффективности фаготерапии при лечении инфекционных заболеваний» / Приоритетная справка №2016132090. 03.08.2016.

4. Пичхадзе И.М. Лечение больных с гнойно-воспалительными осложнениями после эндопротезирования тазобедренного сустава [Текст] / И.М. Пичхадзе [и др.] / Вестн. травматологии и ортопедии им. Н.Н. Приорова. - 2009. - № 3. - С.45-50.

5. Тикунова Н.В. Бактериофаги - враги наших врагов. [Текст] / Н.В. Тикунова, В.В. Власов // Наука из первых рук. - 2013. - №2(5). - С. 58-69.

6. Donelli G, Francolini I, Romoli D, Guaglianone E, Piozzi A, Ragunath C, Kaplan JB. Synergistic activity of dispersin B and cefamandole nafate in inhibition of staphylococcal biofilm growth on polyurethanes. Antimicrob Agents Chemother. 2007 Aug;51(8):2733-40.

7. Hughes K.A. Biofilm susceptibility to bacteriophage attack: the role of phage-borne polysaccharide depolymerase. [Текст] / K.A. Hughes, I.W. Sutherland, M.V. Jones // Microbiology. - 1998. - Vol. 144, - P. 3039-3047.

8. Jurado R.L. Why Shouldn't We Determine the Erythrocyte Sedimentation Rate? [Текст] / R.L. Jurado // Clinical Infectious Diseases. - 2001. - Vol. 33. - P. 548-549.

9. The transition metal gallium disrupts Pseudomonas aeruginosa iron metabolism and has antimicrobial and antibiofilm activity [Текст] / Y. Kaneko, M. Thoendel, O. Olakanmi, B.E. Britigan, P.K. Singh // J Clin Invest. - Apr 2007. - Vol. 117(4). - P. 877-888.

10. Lu T.K. Dispersing biofilms with engineered enzymatic bacteriophage [Текст] / T.K. Lu, J.J. Collins // Proc Natl Acad Sci USA. - 2007. - Vol. 104. - P. 11197-11202.

11. Infections of the musculoskeletal system: basic principles, prevention, diagnosis and treatment. 2nd Edition. [Текст] / P.E Ochsner, O. Borens, P.-M. Bodler. - Schweizerische Gesellschaft für Orthopädie und Traumatologie. - Grandvaux Swiss orthopaedics in-housepublisher, 2014. - P. 260.

12. Parvizi J. Periprosthetic infection: A new prognostic classification. / J. Parvizi, K. Azzam, E. Ghanem, C.D. Valle, R. Barrack // 27th Annual Meeting of the EBJIS. (Barcelona, 2008). Barcelona, 2008.

13. New definition for periprosthetic joint infection, from the Workgroup of the Musculoskeletal Infection Society [Текст] / J. Parvizi, B. Zmistowski, E.F. Berbari et al. // Clin Orthop Relat Res. - 2011. - Vol. 469(11). - P. 2992-4.

14. Renz N. Pocket Guide to Diagnosis \& Treatment of Periprosthetic Joint infection. [Текст] / N. Renz, A. Trampuz. - Berlin: PRO-IMPLANT Foundation, 2015. 
15. Tait K. The efficacy of bacteriophage as a method of biofilm eradication [Текст] / K. Tait, L. Skillman, I. Sutherland // Biofouling. - 2002. - Vol. 18. - P. 305-311. 